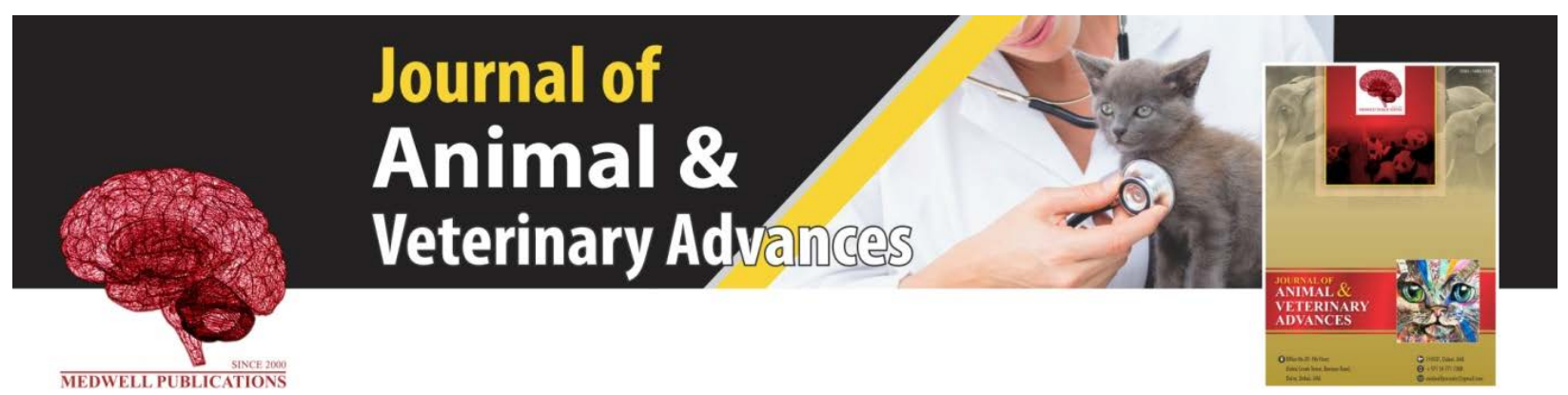

\title{
Effect of Xylazine, Xylazine/Fentanyl and Xylazine/Nalbuphine on Hematological and Serum Biochemical Parameters in Standing Horses
}

${ }^{1}$ Amal Hammad, ${ }^{1}$ Shaaban Gadallah, ${ }^{2}$ Nahed Thabet, ${ }^{1}$ Tarek Misk and ${ }^{1}$ Ahmed Sharshar ${ }^{1}$ Department of Surgery, Anesthesiology and Radiology, Faculty of Veterinary Medicine, ${ }^{2}$ Department of Clinical Pathology, Faculty of Veterinary Medicine, University of Sadat City, 32511 Sadat City, Egypt

Key words: Xylazine, fentanyl, nalbuphine, hematological biochemical, horses

\section{Corresponding Author:}

Amal Hammad

Department of Surgery, Anesthesiology and Radiology, Faculty of Veterinary Medicine, University of Sadat City, 32511 Sadat City, Egypt

Page No.: 26-33

Volume: 19, Issue 3, 2020

ISSN: $1680-5593$

Journal of Animal and Veterinary Advances

Copy Right: Medwell Publications
Abstract: Standing sedation is an efficient alternative to general anesthesia in horses and a necessity is present for development of new sedative combinations with minimal adverse effects. Therefore, this study was designed to investigate the effect of xylazine given alone or in combination with fentanyl or nalbuphine on some hematobiochemical parameters in horses. Five adult healthy horses were randomly assigned to receive three treatments at 1 week interval as follows, XYL group (0.55 $\mathrm{mg} \mathrm{kg}^{-1}$ of xylazine IV); XYL/FEN group $\left(0.55 \mathrm{mg} \mathrm{kg}^{-1}\right.$ of xylazine IV with $4.92 \mu \mathrm{g} \mathrm{kg}^{-1}$ of fentanyl IV) and XYL/NAL (0.55 $\mathrm{mg} \mathrm{kg}^{-1}$ of xylazine IV with $0.3 \mathrm{mg} \mathrm{kg}^{-1}$ of nalbuphine IV).Venous blood samples were collected before (baseline) and at 8, 15, 30, 60, 90 and 120 min after xylazine administration. All studied variables were analyzed using a one-way Analysis of Variance (ANOVA) and the level of significance was set at $\mathrm{p}<0.05$. Significant decrease in Red Blood Cell Count (RBCs), Hemoglobin (Hb) concentrations, Packed Cell Volume (PCV\%) was detected in XYL group at most sampling times compared to XYL/NAL group with the absence of significant alterations in these parameters in XYL/FEN group. Significant decrease in platelet counts was only observed in XYL group. Serum Total Protein (TP) and albumin concentrations were also significantly decreased in XYL group while a significant increase in blood glucose concentrations was observed in XYL/FEN group. Mostly, no significant changes were reported in leukogram, blood $\mathrm{pH}$ and serum levels of electrolytes and minerals with all sedative protocols evaluated in this study. In conclusion, it was found that both fentanyl and nalbuphine were effective in ameliorating 
the depressant effect of xylazine on red blood cell indices, platelet counts and serum concentrations of
TP and albumin, however, fentanyl/xylazine combination may be not recommended in diabetic animals.

\section{INTRODUCTION}

Considering the high morbidity and mortality rates associated with general anesthesia in horses ${ }^{[1-3]}$, many diagnostic and surgical procedures can be conducted in standing sedated animals to enhance patient safety as well as to avoid expenses associated with general anesthesia ${ }^{[4-7]}$. The $\alpha_{2}$-adrenergic agonists are virtually the main-stem component of any standing sedation in horses asxylazine, detomidine and romifidine are routinely used to facilitate various diagnostic and standing surgical interventions ${ }^{[8,9]}$. Despite their intensive use, it is repeatedly reported that sedation produced by these drugs alone is less reliable as the sedated horses may respond unexpectedly to imposed stimuli, especially, to touch which represents a danger both to the horse and personnel involved ${ }^{[10-12]}$. Consequently, many researcher recommended the use of opioids in combination with $\alpha_{2}$-agonists to enhance and prolong their sedative and analgesic effects ${ }^{[13-15]}$.

Fentanyl is a potent opioid analgesic. In horses, fentanyl associated somatic analgesia was demonstrated following intravenous administration ${ }^{[6]}$ as well as following application of transdermal patches ${ }^{[17]}$. Nalbuphine is another opioid analgesic which was found to be effective to enhance the degree of sedation provided by detomidine in ponies ${ }^{[18]}$.

Despite the intensive assessment of xylazine and opioids for achievement of standing sedation in horses ${ }^{[14,7,19]}$. Limited studies were targeted their effects on hemato biochemical profile in horses whereas significant alteration in hemoglobin concentration, $\mathrm{pH}$, blood glucose concentration and some electrolyte levels was recorded during xylazine Constant Rate Infusion (CRI) in horses ${ }^{[20,21]}$ however, others did not demonstrate significant adverse biochemical effects of xylazine given as a single intravenous bolus in combination with buprenorphine ${ }^{[22]}$. To our knowledge the effect of xylazine in combination witheither fentanylor nalbuphine on hematobiochemical parameters was not previously evaluated in sedated horses. Therefore, the aim of the present study was to compare the effect of xylazine when given alone or in combination with fentanylor nalbuphine on complete blood picture and some serum biochemical variables in standing horses.

\section{MATERIALS AND METHODS}

Animals: Five adult mixed breed horses (four males and one female) aged $14.00 \pm 4.95$ years and weighing
$299.80 \pm 6.87 \mathrm{~kg}$ were enrolled in this study. The horses were considered healthy on the bases of physical examination, complete blood count and serum biochemistry analyses. This study was approved by the Ethical Committee of the University of Sadat City.

Study design: For the entire duration of the study, the horses were kept in their stall belonging to University of Sadat City. At the end of the day preceding the experiment, horses were weighed and the hair over right jugular vein was shaved for placement of venous catheter. Food but not water was withheld for $12 \mathrm{~h}$ before the experiment.

On the day of the study, horses were placed in a stock in a quiet room and allowed at least $1 \mathrm{~h}$ to acclimatize to their surroundings. The right jugular vein of each horse was catheterized under local anesthesia with subcutaneous lidocaine $2 \%(2 \mathrm{~mL})$ using a 16 gauge catheter $(45 \mathrm{~mm}$, Harsoria health care, Haryana, India) for administration of drugs and collection of blood samples. The horses then were subjected into each of the following 3 treatments with 1 week washout period in between:

Xylazine group (XYL): Horses received an intravenous dose of $0.55 \mathrm{mg} \mathrm{kg}^{-1}$ of xylazine (Xyla-Ject $20 \mathrm{mg} \mathrm{mL}^{-1}$, Adwia Co, 10th of Ramadan city, Egypt) alone over $1 \mathrm{~min}^{[8]}$.

Xylazine/Fentanyl group (XYL/FEN): An intravenous dose of $4.92 \mu \mathrm{g} \mathrm{kg}^{-1}$ of fentanyl (Fentanyl Hameln $50 \mu \mathrm{g} \mathrm{mL}{ }^{-1}$, Hameln pharmaceutical, Germany) was administered over 2 min following an intravenous bolus of $0.55 \mathrm{mg} \mathrm{kg}^{-1}$ of xylazine at $5 \mathrm{~min}$ interval. Fentanyl dose was calculated using the equation previously described by Thomasy et al. ${ }^{[23]}$ as follows: loading dose $=$ target plasma concentration $\times$ volume of distribution at steady state. According to Thomasy et $a l^{[23]}$, $13.31 \mathrm{ng} \mathrm{mL}^{-1}$ was used as target plasma concentration while $0.37 \mathrm{~L} \mathrm{~kg}^{-1}$ was used as the volume of distribution at steady state according to Thomasy et al. ${ }^{[24]}$.

Xylazine/Nalbuphine group (XYL/NAL): Nalbuphine (Nalufin $20 \mathrm{mg} \mathrm{mL}^{-1}$, Amoun pharmaceutical Co, Cairo, Egypt) was given intravenously at dose of $0.3 \mathrm{mg} \mathrm{kg}^{-1}$ according to Taylor et al. ${ }^{[18]}$ over 2 min following an intravenous bolus of $0.55 \mathrm{mg} \mathrm{kg}^{-1}$ of xylazine at $5 \mathrm{~min}$ interval.

Blood collection: The $5 \mathrm{~mL}$ venous blood sample was collected before (baseline) and at 8, 15, 30, 60, 90 and 
120 min after xylazine administration. About $0.5 \mathrm{~mL}$ was placed in EDTA tubes for Complete Blood Count (CBC). The rest $4.5 \mathrm{~mL}$ of blood was placed in plain tubes with subsequent centrifugation at $1600 \mathrm{~g}$ for $14 \mathrm{~min}$ for separation of serum using a serum centrifuge (tabletop low speed centrifuge TDL-60B, Spain). The harvested serum samples were stored at $-80^{\circ} \mathrm{C}$ for subsequent biochemical analysis. Another $3 \mathrm{~mL}$ of heparinized blood samples were collected for assessment of plasma $\mathrm{pH}$ for evaluation of acid-base status.

Evaluation of hematobiochemical parameters: The evaluated hematological parameters included Red Blood Cell (RBCs) count, Hemoglobin (Hb) concentration, Packed Cell Volume (PCV\%), total (TLC) and differential leukocytic counts as well as and platelet counts. These hematological indices were performed using 3-part differential veterinary hematology analyzer (Avantor performance materials, USA. Serum samples were investigated for concentrations of Total Protein (TP), albumin, glucose, sodium $\left(\mathrm{Na}^{+}\right)$, potassium $\left(\mathrm{K}^{+}\right)$, Chloride $\left(\mathrm{Cl}^{-}\right)$, Calcium $\left(\mathrm{Ca}^{2+}\right)$ and inorganic phosphorus $\left(\mathrm{Ph}^{2+}\right)$. All serum biochemical parameters were measured by spectrophotometric method (Unico spectrophotometer UV
480, USA) using commercial kits and following the manufacturer's instructions. Plasma $\mathrm{pH}$ was assessed at $37^{\circ} \mathrm{C}$ without correctionto the horse body temperature using a pH meter (Hanna instruments, Romania).

Statistical analysis: Statistical analysis was performed with SPSS 16.0 Software (SPSS, USA). The studied hematobiochemical parameters were analyzed using a one-way Analysis of Variance (ANOVA) with Dunnett's post-test for comparisons of means within each group in relation to baseline. Comparisons between groups at each time were performed with one-way ANOVA followed by Tukey's test. Results are presented as mean \pm standard deviation. The level of significance was set at $\mathrm{p}<0.05$.

\section{RESULTS AND DISCUSSION}

There were no significant differences between treatments in baseline values of the studied hematological and biochemical variables (Table 1-3 and Fig. 1-4). Compared to baseline, significant decrease in RBCs counts and $\mathrm{Hb}$ concentrations was detected in XYL group at all recording time periods except at 90 min while PCV values showed a significant decrease at 8,15 and

Table 1: Red Blood Cell (RBCs) counts, Packed Cell Volume (PCV\%) and Hemoglobin (Hb) concentrations in five horses after Xylazine (XYL), Xylazine/Fentanyl (XYL/FEN) and Xylazine/Nalbuphine (XYL/NAL) administration

\begin{tabular}{|c|c|c|c|c|c|c|c|c|}
\hline \multirow[b]{2}{*}{ Variables } & \multirow[b]{2}{*}{ Treatments } & \multirow[b]{2}{*}{ Baseline } & \multicolumn{6}{|l|}{ Time (min) } \\
\hline & & & 8 & 15 & 30 & 60 & 90 & 120 \\
\hline \multirow[t]{3}{*}{$\overline{\operatorname{RBCs}\left(\times 10^{6} \mu \mathrm{L}^{-1}\right)}$} & XYL & $12.57 \pm 0.45$ & $8.15 \pm 1.25^{*}$ & $9.63 \pm 1.09 *$ & $10.15 \pm 1.20^{*}$ & $9.57 \pm 1.61^{*}$ & $12.18 \pm 0.27$ & $9.36 \pm 0.35 *$ \\
\hline & XYL/FEN & $12.03 \pm 0.55$ & $10.93 \pm 1.61$ & $10.99 \pm 1.17$ & $12.14 \pm 1.54$ & $11.880 \pm 0.68$ & $11.08 \pm 1.57$ & $12.45 \pm 1.15$ \\
\hline & XYL/NAL & $11.88 \pm 0.17$ & $10.44 \pm 1.50$ & $9.23 \pm 0.89 *$ & $10.86 \pm 1.14$ & $11.39 \pm 1.83$ & $11.20 \pm 0.60$ & $9.08 \pm 0.27 *$ \\
\hline \multirow[t]{3}{*}{$\mathrm{Hb}\left(\mathrm{g} \mathrm{dL}^{-1}\right)$} & XYL & $17.67 \pm 1.53$ & $13.33 \pm 1.53^{*}$ & $14.13 \pm 0.81 *$ & $14.33 \pm 1.53^{*}$ & $13.100 \pm 2.15^{*}$ & $15.93 \pm 0.50$ & $12.07 \pm 0.90 *$ \\
\hline & XYL/FEN & $16.33 \pm 2.31$ & $14.25 \pm 4.05$ & $14.35 \pm 3.45$ & $16.72 \pm 2.42$ & $15.40 \pm 1.80$ & $13.20 \pm 2.90$ & $17.00 \pm 1.73 \dagger$ \\
\hline & XYL/NAL & $15.00 \pm 1.00$ & $13.27 \pm 1.30$ & $12.33 \pm 1.53$ & $14.33 \pm 1.26$ & $14.93 \pm 1.40$ & $14.47 \pm 1.06$ & $9.93 \pm 0.93 *$ \\
\hline \multirow[t]{3}{*}{ PCV (\%) } & XYL & $50.33 \pm 2.52$ & $38.73 \pm 3.25^{*}$ & $39.78 \pm 1.94 *$ & $43.47 \pm 3.40$ & $43.13 \pm 4.37$ & $46.90 \pm 1.08$ & $36.74 \pm 6.56^{*}$ \\
\hline & XYL/FEN & $49.67 \pm 2.52$ & $44.75 \pm 5.60$ & $43.80 \pm 6.40$ & $51.22 \pm 5.45$ & $49.28 \pm 1.11$ & $46.01 \pm 7.43$ & $52.93 \pm 3.10 \dagger$ \\
\hline & XYL/NAL & $49.00 \pm 2.65$ & $43.37 \pm 6.86$ & $42.57 \pm 2.40$ & $45.23 \pm 6.64$ & $47.53 \pm 7.97$ & $46.90 \pm 3.34$ & $35.63 \pm 1.17 *$ \\
\hline
\end{tabular}

*Significant difference $(\mathrm{p}<0.05)$ from baseline; †Significant difference $(\mathrm{p}<0.05)$ from other treatments; Data are expressed as mean \pm SD

Table 2: Total (TLC) and differential leukocytic and platelet counts in five horses after Xylazine (XYL), Xylazine/Fentanyl (XYL/FEN) and Xylazine/Nalbuphine (XYL/NAL) administration

\begin{tabular}{|c|c|c|c|c|c|c|c|c|}
\hline \multirow[b]{2}{*}{ Variables } & \multirow[b]{2}{*}{ Treatments } & \multirow[b]{2}{*}{ Baseline } & \multicolumn{6}{|l|}{ Time (min) } \\
\hline & & & 8 & 15 & 30 & 60 & 90 & 120 \\
\hline TLC & XYL & $7.67 \pm 1.53$ & $7.87 \pm 3.46$ & $7.43 \pm 2.86$ & $6.90 \pm 1.65$ & $7.97 \pm 3.87$ & $7.13 \pm 1.63$ & $8.50 \pm 1.32$ \\
\hline \multirow{2}{*}{$\left(\times 10^{3} \mu \mathrm{L}^{-1}\right)$} & XYL/FEN & $7.10 \pm 0.36$ & $5.30 \pm 1.47$ & $5.63 \pm 0.76$ & $5.33 \pm .850$ & $5.80 \pm 0.85$ & $5.80 \pm 0.69$ & $4.50 \pm 1.41^{*}$ \\
\hline & XYL/NAL & $6.80 \pm 1.31$ & $7.43 \pm 1.52$ & $7.10 \pm 1.78$ & $7.50 \pm 2.60$ & $6.30 \pm 2.36$ & $6.57 \pm 2.55$ & $7.90 \pm 2.82$ \\
\hline Neutrophils & XYL & $5.90 \pm 0.87$ & $5.57 \pm 1.74$ & $5.67 \pm 1.69$ & $5.30 \pm 1.25$ & $5.53 \pm 3.93$ & $5.53 \pm 1.27$ & $6.50 \pm 0.89$ \\
\hline \multirow[t]{2}{*}{$\left(\times 10^{3} \mu \mathrm{L}^{-1}\right)$} & XYL/FEN & $5.50 \pm 0.61$ & $4.33 \pm 1.02$ & $4.33 \pm 0.96$ & $3.60 \pm 1.05$ & $4.67 \pm 0.81$ & $4.57 \pm 0.68$ & $3.23 \pm 1.27 *$ \\
\hline & XYL/NAL & $5.63 \pm 1.44$ & $6.20 \pm 1.83$ & $5.60 \pm 1.95$ & $6.23 \pm 2.55$ & $5.17 \pm 2.16$ & $5.53 \pm 2.47$ & $6.03 \pm 2.44$ \\
\hline Lymphocytes & XYL & $1.67 \pm 0.64$ & $2.00 \pm 1.82$ & $1.53 \pm 1.18$ & $1.40 \pm 0.40$ & $1.97 \pm 0.70$ & $1.37 \pm 0.32$ & $1.77 \pm 0.61$ \\
\hline \multirow[t]{2}{*}{$\left(\times 10^{3} \mu L^{-1}\right)$} & XYL/FEN & $1.23 \pm 0.31$ & $0.80 \pm 0.46$ & $1.07 \pm 0.29$ & $1.33 \pm 0.12$ & $1.00 \pm 0.10$ & $1.07 \pm 0.12$ & $0.85 \pm 0.35$ \\
\hline & XYL/NAL & $0.93 \pm 0.29$ & $1.00 \pm 0.26$ & $1.20 \pm 0.60$ & $1.07 \pm 0.15$ & $0.93 \pm 0.15$ & $0.83 \pm 0.06$ & $1.45 \pm 0.64$ \\
\hline Monocytes & XYL & $0.17 \pm 0.06$ & $0.30 \pm 0.17$ & $0.23 \pm 0.15$ & $0.20 \pm 0.10$ & $0.47 \pm 0.39$ & $0.23 \pm 0.06$ & $0.23 \pm 0.06$ \\
\hline \multirow[t]{2}{*}{$\left(\times 10^{3} \mu \mathrm{L}^{-1}\right)$} & XYL/FEN & $0.37 \pm 0.29$ & $0.17 \pm 0.06$ & $0.23 \pm 0.15$ & $0.40 \pm 0.35$ & $0.13 \pm 0.06$ & $0.17 \pm 0.06$ & $0.37 \pm 0.29$ \\
\hline & XYL/NAL & $0.23 \pm 0.06$ & $0.23 \pm 0.06$ & $0.30 \pm 0.10$ & $0.20 \pm 0.10$ & $0.20 \pm 0.10$ & $0.20 \pm 0.10$ & $0.33 \pm 0.15$ \\
\hline & XYL & $174.67 \pm 22.03$ & $109.33 \pm 25.32 *$ & $146.00 \pm 33.51$ & $160.00 \pm 17.32$ & $118.33 \pm 18.93$ & $151.67 \pm 24.66$ & $110.00 \pm 36.06^{*}$ \\
\hline \multirow[t]{2}{*}{$\left(\times 10^{3} \mu \mathrm{L}^{-1}\right)$} & XYL/FEN & $165.00 \pm 32.79$ & $150.00 \pm 26.46$ & $110.00 \pm 36.06$ & $150.00 \pm 34.64$ & $141.00 \pm 46.18$ & $180.00 \pm 26.46$ & $163.33 \pm 63.51$ \\
\hline & XYL/NAL & $155.00 \pm 47.69$ & $151.67 \pm 27.54$ & $183.33 \pm 55.07$ & $163.33 \pm 41.63$ & $135.33 \pm 39.31$ & $166.67 \pm 41.63$ & $183.33 \pm 35.12$ \\
\hline
\end{tabular}


J. Anim. Vet. Adv., 19 (3): 26-33, 2020

Table 3: Serum levels of electrolytes and minerals including sodium $\left(\mathrm{Na}^{+}\right)$, potassium $\left(\mathrm{K}^{+}\right)$, Chloride $\left(\mathrm{Cl}^{-}\right)$, Calcium $\left(\mathrm{Ca}^{2+}\right)$ and inorganic phosphorus $\left(\mathrm{Ph}^{2+}\right)$ in five horses after Xylazine (XYL), Xylazine/Fentanyl (XYL/FEN) and Xylazine/Nalbuphine (XYL/NAL) administration

\begin{tabular}{|c|c|c|c|c|c|c|c|c|}
\hline \multirow[b]{2}{*}{ Variables } & \multirow[b]{2}{*}{ Treatments } & \multirow[b]{2}{*}{ Baseline } & \multicolumn{6}{|l|}{ Time (min) } \\
\hline & & & 8 & 15 & 30 & 60 & 90 & 120 \\
\hline \multirow[t]{3}{*}{$\mathrm{Na}^{+}\left(\mathrm{mmol} \mathrm{L}^{-1}\right)$} & XYL & $129.87 \pm 4.14$ & $131.60 \pm 7.29$ & $127.55 \pm 5.50$ & $135.94 \pm 9.97$ & $129.21 \pm 3.69$ & $133.44 \pm 7.25$ & $124.83 \pm 9.82$ \\
\hline & XYL/FEN & $127.57 \pm 7.34$ & $129.33 \pm 2.08$ & $135.65 \pm 6.86$ & $127.07 \pm 4.09$ & $122.40 \pm 8.29$ & $118.22 \pm 5.58$ & $116.38 \pm 10.15$ \\
\hline & XYL/NAL & $128.01 \pm 3.93$ & $120.29 \pm 7.51$ & $131.16 \pm 7.09$ & $131.05 \pm 6.77$ & $131.39 \pm 5.29$ & $130.86 \pm 9.32$ & $135.60 \pm 5.16$ \\
\hline \multirow[t]{3}{*}{$\mathrm{K}^{+}\left(\mathrm{mmol} \mathrm{L}^{-1}\right)$} & XYL & $4.75 \pm 0.46$ & $4.95 \pm 0.20$ & $5.31 \pm 0.40$ & $5.10 \pm 0.26$ & $5.69 \pm 0.76 \dagger$ & $5.43 \pm 0.25$ & $5.06 \pm 0.08$ \\
\hline & XYL/FEN & $4.57 \pm 0.29$ & $4.44 \pm 0.29$ & $4.46 \pm 0.35$ & $4.42 \pm 0.29$ & $4.06 \pm 0.71$ & $4.82 \pm 0.46$ & $4.65 \pm 0.29$ \\
\hline & XYL/NAL & $4.67 \pm 0.29$ & $4.04 \pm 0.67$ & $4.54 \pm 0.52$ & $4.65 \pm 0.38$ & $4.35 \pm 0.62$ & $4.59 \pm 0.63$ & $4.63 \pm 0.64$ \\
\hline \multirow[t]{3}{*}{$\mathrm{Cl}^{-}\left(\mathrm{mmol} \mathrm{L}{ }^{-1}\right)$} & XYL & $93.11 \pm 3.58$ & $88.00 \pm 6.25$ & $87.33 \pm 7.37$ & $88.23 \pm 6.92$ & $86.00 \pm 6.24$ & $87.19 \pm 7.85$ & $87.96 \pm 5.34$ \\
\hline & XYL/FEN & $93.54 \pm 3.93$ & $93.18 \pm 2.84$ & $98.88 \pm 6.82$ & $88.14 \pm 7.64$ & $86.94 \pm 6.00$ & $89.46 \pm 6.08$ & $88.04 \pm 6.32$ \\
\hline & XYL/NAL & $93.06 \pm 5.80$ & $93.43 \pm 5.81$ & $95.63 \pm 3.72$ & $99.05 \pm 1.65$ & $99.93 \pm 5.54$ & $97.37 \pm 7.39$ & $94.58 \pm 6.92$ \\
\hline \multirow[t]{3}{*}{$\mathrm{Ca}^{2+}\left(\mathrm{mg} \mathrm{dL}^{-1}\right)$} & XYL & $10.86 \pm 0.24$ & $11.46 \pm 0.38$ & $11.28 \pm 0.77$ & $11.96 \pm 0.59 \dagger$ & $10.93 \pm 0.83$ & $11.34 \pm 0.29$ & $11.50 \pm 0.69$ \\
\hline & XYL/FEN & $10.75 \pm 0.23$ & $10.39 \pm 0.88$ & $10.36 \pm 0.84$ & $9.77 \pm 0.03$ & $10.21 \pm 0.38$ & $10.51 \pm 0.13$ & $10.50 \pm 0.73$ \\
\hline & XYL/NAL & $10.80 \pm .105$ & $10.54 \pm 0.96$ & $10.58 \pm 0.20$ & $10.69 \pm 0.95$ & $10.73 \pm 0.86$ & $10.43 \pm 0.34$ & $10.79 \pm 0.61$ \\
\hline \multirow[t]{3}{*}{$\mathrm{Ph}^{2+}\left(\mathrm{mg} \mathrm{dL}{ }^{-1}\right)$} & XYL & $3.22 \pm 0.27$ & $3.15 \pm 0.22$ & $3.08 \pm 0.37$ & $3.21 \pm 0.26$ & $3.04 \pm 0.026$ & $2.99 \pm 0.26$ & $3.03 \pm 0.21$ \\
\hline & XYL/FEN & $3.18 \pm 0.10$ & $3.31 \pm 0.16$ & $3.22 \pm 0.16$ & $3.19 \pm 0.32$ & $2.93 \pm 0.09$ & $2.88 \pm 0.24$ & $3.14 \pm 0.14$ \\
\hline & XYL/NAL & $3.21 \pm 0.09$ & $2.88 \pm 0.18$ & $2.98 \pm 0.21$ & $3.05 \pm 0.10$ & $2.60 \pm 0.58$ & $3.16 \pm 0.16$ & $3.32 \pm 0.29$ \\
\hline
\end{tabular}

†Significant difference $(\mathrm{p}<0.05)$ between $\mathrm{XYL}$ and XYL/FEN; Data are expressed as mean \pm SD

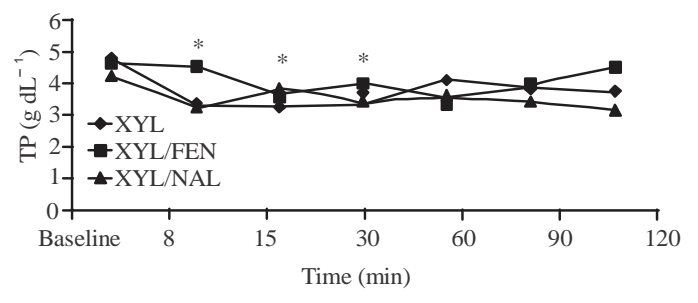

Fig. 1: Mean serum concentrations of Total Protein (TP) in five horses after receiving Xylazine (XYL), Xylazine/Fentanyl (XYL/FEN) and Xylazine/Nalbuphine (XYL/NAL) treatments. *Significant difference between XYL and baseline values

120 min. In XYL/NAL group, significant decrease in RBCs counts was recorded at 15 and 120 min but $\mathrm{Hb}$ and PCV values were significantly decreased only at $120 \mathrm{~min}$. Comparing treatments, there were no significant differences in RBCs counts between the three treatment protocols over the entire observation period while at $120 \mathrm{~min}, \mathrm{PCV}$ and $\mathrm{Hb}$ values were significantly higher in XYL/FEN compared to XYL and XYL/NAL (Table 1). Significant decrease than baseline in total leukocytic and neutrophil counts was only detected at $120 \mathrm{~min}$ in XYL/FEN group. No significant changes were observed in lymphocyte and monocyte counts in any treatment group compared to baseline.In addition, total leukocytic, neutrophil, lymphocyte and monocyte counts did not vary significantly between groups. Platelet counts were significantly lower than baseline at 8 and 120 min only in XYL group while no significant differences were detected among other treatment groups (Table 2). In XYL group, significant decrease in TP compared to baseline values was detected up to $30 \mathrm{~min}$ with significant decrease in albumin concentration only at 8 and 15 min (Fig. 1 and 2).

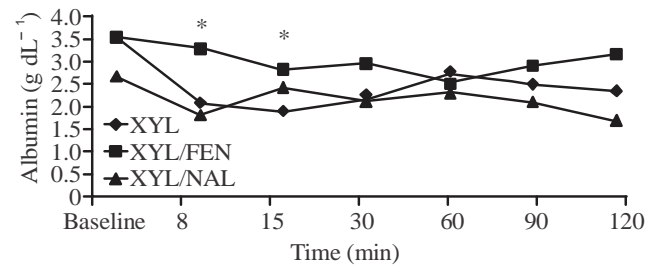

Fig. 2: Mean serum concentrations of albumin in five horses after receiving Xylazine (XYL), Xylazine/Fentanyl (XYL/FEN) and Xylazine/Nalbuphine (XYL/NAL) treatments. *Significant difference between XYL and baseline values

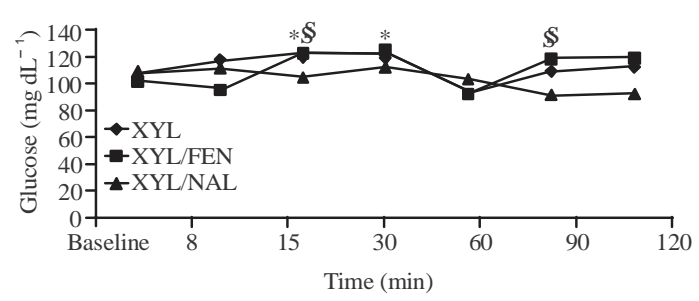

Fig. 3: Mean serum concentrations of glucose in five horses after receiving xylazine (XYL), Xylazine/Fentanyl (XYL/FEN) and Xylazine/Nalbuphine (XYL/NAL) treatments. *Significant difference between XYL/FEN and baseline values. § Significant difference between $\mathrm{XYL} / \mathrm{FEN}$ and XYL/NAL

No significant changes in TP and albumin levels were evident in other groups compared to baseline or between treatment groups at any time point. Significant elevation in blood glucose concentrations was detected in XYL/FEN group at 15 and 30 min compared to baseline values and at 15 and $90 \mathrm{~min}$ when compared to XYL/NAL group (Fig. 3). 


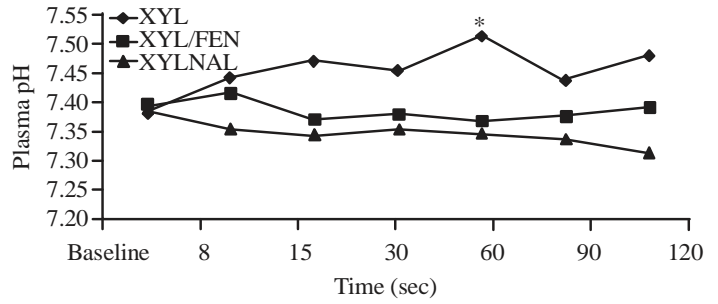

Fig. 4: Mean plasma $\mathrm{pH}$ in five horses after receiving Xylazine (XYL), Xylazine/Fentanyl (XYL/FEN) and Xylazine/Nalbuphine (XYL/NAL) treatments. *Significant difference between XYL and baseline values

Data regarding changes in electrolyte levels are listed in Table 3 and the results showed that significant alterations in $\mathrm{Na}^{+}$levels did not occur in any group relative to baseline nor between treatment groups. In all groups, $\mathrm{K}^{+}$levels did not show significant changes than baseline while it was being significantly higher in XYL group compared to XYL/FEN at only $60 \mathrm{~min}$. In all treatment groups, there were no significant changes in serum $\mathrm{Cl}^{-}$levels compared to baseline as well as among groups. Over the entire observation period, $\mathrm{Ca}^{2+}$ levels did not vary significantly than baseline in all treatment groups, however at $30 \mathrm{~min}$, XYL group demonstrated significant elevation in $\mathrm{Ca}^{2+}$ levels than XYL/FEN group. Serum $\mathrm{Ph}^{2+}$ levels did not change significantly in any group than baseline values nor among treatment groups. Significant elevation in $\mathrm{pH}$ were only detected in XYL group at 60 min with no significant differences between groups at any observation period (Fig. 4).

Under the conditions of the present study, administration of xylazine alone was associated with a significant reduction in RBCs counts. Similar findings were demonstrated in a previous study ${ }^{[25]}$ where xylazine was given intravenously to mares at dose of $0.5 \mathrm{mg} \mathrm{kg}^{-1}$. Marked reduction in $\mathrm{Hb}$ concentrations was also noticed following xylazine administration. This result was like data reported in horses following intravenous administration of equipotent dose of detomidine $\left(10 \mu \mathrm{g} \mathrm{kg}^{-1}\right)^{[26]}$. Decreases in PCV were previously reported following xylazine administration to horses ${ }^{[27,25]}$. In the same way, xylazine induced a marked drop in PCV values in the present study. These findings could be attributed tothe xylazine-associated increase in plasma osmolality which might induce fluid shift into the intravascular space ${ }^{[25]}$. Decreased PCV could also be explained in terms of reduced sympathetic tone resulting from sedation with $\alpha_{2}$-agonists with subsequent splenic relaxation and RBC sequestration ${ }^{[27]}$. This factor could be an important contributing factor in the present study based on the pronounced sedation exhibited by horses following xylazine administration. Initial hypertension followed by hypotension is a characteristic biphasic effect of xylazine on blood pressure in horses ${ }^{[28]}$. However, initial hypertension was not be detected in xylazine group as it might be of very short duration (data are not shown) this hypertensive phase might be prolonged by fentanyl administration. Some researchers previously attributed the initial hypertension following administration of $\alpha_{2}$-agonists to drugs-induced increase in systemic vascular resistance ${ }^{[27]}$. Based on this explanation, vascular tone could be increased in fentanyl group which could prevent splenic sequestration of RBC and consequently limit the effect of this combination on red cell parameters. Another explanation for these results could also be attributed to the reported minimal effect of fentanyl on PCV when it was given as a single intravenous bolus $\left(4 \mu \mathrm{gg}^{-1}\right)$ to awake horses ${ }^{[24]}$.

A recent study by Kinter et al. ${ }^{[29]}$ evaluated the effect of intravenous xylazine administration at dose of $0.5 \mathrm{mg}$ $\mathrm{kg}^{-1}$ to horses and revealed that xylazine did not induce clinically significant alterations in leukocyte numbers. Consistently, administration of xylazine alone (XYL group) in our study did not induce important changes in both total and differential leucocytic counts. Likewise, minimal impact on white blood cell parameters was observed in both XYL/FEN and XYL/NAL groups indicated by pronounced reduction in total leukocytic and neutrophil countsonly at $120 \mathrm{~min}$ in XYL/FEN group. This reduction although being statistically significant it was very mild. In contrast to these results, a significant increase in total leucocytic, lymphocyte and neutrophil counts were recorded following fentanyl administration intravenously to dogs at dose of $5 \mathrm{a} \mu \mathrm{g} \mathrm{kg}^{-1[30]}$. Despite the approximately similar doses used in both studies, the discrepancy could be mainly resulted from species difference that might be accompanied with different drug behavior.

Administration of xylazine (XYL group) was associated with a significant decrease in TP for the first $30 \mathrm{~min}$. Albumin concentrations were also significantly decreased during the first $15 \mathrm{~min}$. These findings denoted that reduction of albumin concentrations was the main factor implicated in decreased TP. Clinically significant reduction in total solids was consistently observed after administration of different $\alpha_{2}$-agonists like xylazine ${ }^{[25]}$ and dexmedetomidine ${ }^{[31]}$ to horses. The decrement in albumin and TP concentrations in the present study could be attributed to xylazine associated increase in plasma osmolality which might induce fluid shift into the intravascular space ${ }^{[25]}$. When xylazine was given in combination with Fentanyl (XYL/FEN) or Nalbuphine (XYL/NAL) no significant alterations were determined in $\mathrm{TP}$ and albumin concentrations. In disagreement with these results, significant reduction in TP was recorded following medetomidine administration to horses with maintenance of this reduction even following morphine administration ${ }^{[32]}$. 
Hyperglycemia was previously described in horses after administration of single doses of different $\alpha_{2}$-adrenergic agonists ${ }^{[33]}$. Some researcher explained this alteration to be mediated by interaction with post synaptic $\alpha_{2}$-adrenergic receptors of pancreatic $\beta$-cells with subsequent reduction of insulin releas $\mathrm{e}^{[26,34]}$. Other sites of action as hepatic tissue as well as involvement of $\alpha_{1}$-adrenergic receptors and imidazoline receptors were proposed by Ambrisko and Hikasa ${ }^{[35]}$ and Kanda and Hikasa $^{[36]}$. An elevation in blood glucose concentration was also detected in the present study following xylazine administration however, the prominent finding here that such elevation was insignificant compared to baseline. On contrary, in another previous study, significant increase in blood glucose was evident where xylazine was given intravenously as a loading dose $\left(1 \mathrm{mg} \mathrm{kg}^{-1}\right)$ followed by constant rate infusion $\left(0.69 \mathrm{mg} \mathrm{kg}^{-1} / \mathrm{h}\right)$ to horses ${ }^{[21]}$. The difference in the results between the two studies could be based mainly on the lower dose used in our study which might limit the hyperglycemic effect of xylazine. Administration of nalbuphine along with xylazine did not confer any alteration than that observed in xylazine group. On the other hand when fentanyl was given in combination with xylazine significant increase in serum glucose concentration was recorded at some observation periods. In agreement with these findings, plasma glucosecon centrations increased significantly after detomidine buprenorphine injection in horses ${ }^{[37]}$. Our explanation for this includes that, fentanyl might potentiate the hyperglycemic effect of xylazine whereas fentanyl alone was not able clinically to have significant effects on biochemical parameters in horse ${ }^{[38]}$.

In the present study, no significant changes in $\mathrm{Na}^{+}$ levels were detected after xylazine administration. On Contrary, some reports demonstrated either significant increase $^{[25]}$ or decrease ${ }^{[21]}$ in xylazine treated horses. Insignificant reduction was observed in $\mathrm{Cl}$ levels following xylazine injection which may be induced by xylazine-associated increase clexcretion in horses ${ }^{[39]}$. In contrast, Ringer et al. ${ }^{[25]}$ found significant decrement in $\mathrm{Cl}$ levels following xylazine injection.

Slight elevation in $\mathrm{K}^{+}$levels was noted along the entire observation period in XYL group. However, not being statistically significant, the tendency for $\mathrm{K}^{+}$levels to be increased in this group compared to other groups with significant increase at 60 min compared to XYL/FEN might be attributed to decreased renal excretion of $\mathrm{K}^{+}$that could be induced by pronounced reduction of blood pressure seen in this group relative to others (Data are not shown). Furthermore, insulin is known to enhance shift of potassium intracellularly ${ }^{[40]}$, therefore, the anticipated decrease in serum insulin levels in xylazine group could be contributed in part in the development of slight hyperkalemia seen in this group. In agreement with these results, no significant alterations in $\mathrm{K}^{+}$levels were observed by other researchers following xylazine administration $^{[25]}$. No significant changes were observed in serum levels of electrolytes in XYL/FEN and XYL/NAL groups. Similar findings were reported during xylazine/remifentanil constant rate infusionin horses ${ }^{[41]}$. In the same way, xylazine and buprenorphine given in combination to horses did not induce any significant changes in serum $\mathrm{Na}^{+}$and $\mathrm{K}^{+}$levels ${ }^{[22]}$.

Slight elevation in $\mathrm{pH}$ with significant increase at 60 min was observed in XYL group which implicates the presence of alkalosis at this time period. This could be explained by the pronounced elevation in potassium levels seen at this time point whereas $\mathrm{H}^{+}$ions could be pumped intracellularly instead of potassium to maintain the electrical neutrality leading to decreased $\mathrm{H}^{+}$ions in serum and thus, the slight elevation in blood $\mathrm{pH}^{[42,40]}$. In contrast, some authors did not demonstrate any significant alterations in $\mathrm{pH}$ following xylazine administration $^{[25]}$. In XYL/FEN and XYL/NAL, no significant changes in $\mathrm{pH}$ were detected. Similarly, no significant alterations in $\mathrm{pH}$ were observed when xylazine was used in combination with remifentanil ${ }^{[42]}$ or buprenorphine ${ }^{[22]}$ in horses.

\section{CONCLUSION}

Administration of fentanyl or nalbuphine in combination with xylazine ameliorated the depressant effect of xylazine on red blood cell indices, platelet counts and TP and albumin concentrations. In addition, only XYL/FEN combination being accompanied with a pronounced hyperglycemic effect.

\section{ACKNOWLEDGEMENTS}

Researcher thank the staff within their departments for their assistance during the study period.

\section{REFERENCES}

01. Klein, L., 1990. Anesthetic complications in the horse. Vet. Clinics N. Am.: Equine Pract., 6: 665-692.

02. Johnston, G.M., J.K. Eastment, J.L.N. Wood and P.M. Taylor, 2002. The confidential enquiry into perioperative equine fatalities (CEPEF): Mortality results of Phases 1 and 2. Vet. Anaesth. Analg., 29: 159-170.

03. Clarke, K.W., C.M. Trim and L.W. Hall, 2014. Anaesthesia of the Horse. In: Veterinary Anaesthesia, Clarke, K.W., C.M. Trim and L.W. Hall (Eds.). Saunders Elsevier, Oxford, UK., pp: 266-268.

04. Muir, W.W., 2009. Anxiolytics, Nonopioid Sedative-Analgesics and Opioidanalgesics. In: Equine Anesthesia: Monitoring and Emergency Therapy, Muir, W.W. and Hubbell, J.A. (Eds.). Saunders Elsevier, St. Louis, Missouri, pp: 185-209. 
05. Wagner, A.E., K.R. Mama, E.K. Contino, D.J. Ferris and C.E. Kawcak, 2011. Evaluation of sedation and analgesia in standing horses after administration of xylazine, butorphanol and subanesthetic doses of ketamine. J. Am. Vet. Med. Assoc., 238: 1629-1633.

06. Ringer, S.K., K.G. Portier, I. Fourel and R. Bettschart-Wolfensberger, 2012a. Development of a romifidine constant rate infusion with or without butorphanol for standing sedation of horses. Vet. Anaesth. Analg., 39: 12-20.

07. Ringer, S.K., K.G. Portier, I. Fourel and R. Bettschart-Wolfensberger, 2012b. Development of a xylazine constant rate infusion with or without butorphanol for standing sedation of horses. Vet. Anaesth. Analg., 39: 1-11.

08. Fernandes de Souza, J.F., E.R. Monteiro, D. Campagnol, R.C. Ramos and A.M.F. Frasson, 2012. Evaluation of nociception, sedation and cardiorespiratory effects of a constant rate infusion of xylazine alone or in combination with lidocaine in horses. J. Equine Vet. Sci., 32: 339-345.

09. Vigani, A. and F.L. Garcia-Pereira, 2014. Anesthesia and analgesia for standing equine surgery. Vet. Clinics: Equine Pract., 30: 1-17.

10. Alitalo, I., 1986. Clinical experiences with Domosedan (R) in horses and cattle, a review. Acta Vet. Scand. Suppl., 82: 193-196.

11. England, G.C., K.W. Clarke and L. Goossens, 1992. A comparison of the sedative effects of three alpha 2-adrenoceptor agonists (romifidine, detomidine and xylazine) in the horse. J. Vet. Pharmacol. Ther., 15: $194-201$.

12. Corletto, F., A.A. Raisis and J.C. Brearley, 2005. Comparison of morphine and butorphanol as pre-anaesthetic agents in combination with romifidine for field castration in ponies. Vet.Anaesth. Analg., 32: $16-22$.

13. Clarke, K.W., G.C.W. England and L. Goossens, 1991. Sedative and cardiovascular effects of romifidine, alone and in combination with butorphanol, in the horse. J. Vet. Anaesth., 18: 25-29.

14. Seo, J.P., W.G. Son, S. Gang and I. Lee, 2011. Sedative and analgesic effects of intravenous xylazine and tramadol on horses. J. Vet. Sci., 12: 281-286.

15. Gozalo-Marcilla, M., S.P. Luna, N. Crosignani, P.J.N. Filho, F.S. Possebon, L. Pelligand and P.M. Taylor, 2017. Sedative and antinociceptive effects of different combinations of detomidine and methadone in standing horses. Vet. Anaesth. Analg., 44: 1116-1127.

16. Sanchez, L.C., S.A. Robertson, L.K. Maxwell, K. Zientek and C. Cole, 2007. Effect of fentanyl on visceral and somatic nociception in conscious horses. J. Vet. Internal Med., 21: 1067-1075.
17. Wegner, K., R.P. Franklin, M.T. Long and S. Robertson, 2002. How to use fentanyl transdermal patches for analgesia in horses. Proc. Am. Assoc. Equine Pract., 48: 291-294.

18. Taylor, P.M., H. Rymaszewska and S.S. Young, 1990. Evaluation of combinations of nalbuphine with acepromazine or detomidine for sedation in ponies. Vet. Anaesth. Analg., 17: 38-41.

19. Ruiz, J.D., D.A. Zuluaga, I.C. Ruiz, D. Duque, M.C. Ochoa and T. Escobar, 2015. Evaluation of sedation and analgesia protocols with xylazine and two rates of morphine by continuous infusion in stationary horses undergoing laparoscopic castration. Arch. Med. Vet., 47: 333-340.

20. Ringer, S.K., C.C. Schwarzwald, K.G. Portier, A. Ritter and R. Bettschart-Wolfensberger, 2013a. Effects on cardiopulmonary function and oxygen delivery of doses of romifidine and xylazine followed by constant rate infusions in standing horses. Vet. J., 195: 228-234.

21. Ringer, S.K., C.C. Schwarzwald, K. Portier, J. Mauch, A. Ritter and R. Bettschart-Wolfensberger, 2013b. Blood glucose, acid-base and electrolyte changes during loading doses of alpha2-adrenergic agonists followed by constant rate infusions in horses. Vet. J., 198: 684-689.

22. Cruz, F.S., A.B. Carregaro, M. Machado and R.R. Antonow, 2011. Sedative andcardiopulmonary effects of buprenorphine and xylazine in horses. Can. J. Vet. Res., 75: 35-41.

23. Thomasy, S.M., E.P. Steffey, K.R. Mama, A. Solano and S.D. Stanley, 2006. The effects of iv fentanyl administration on the minimum alveolar concentration of isoflurane in horses. BJA: Br. J. Anaesth., 97: 232-237.

24. Thomasy, S.M., K.R. Mama, K. Whitley, E.P. Steffey and S.D. Stanley, 2007. Influence of general anaesthesia on the pharmacokinetics of intravenous fentanyl and its primary metabolite in horses. Equine Vet. J., 39: 54-58.

25. Kullmann, A., M. Sanz, G.T. Fosgate, M.N. Saulez and P.C. Page et al., 2014. Effects of xylazine, romifidine or detomidine on hematology, biochemistry and splenic thickness in healthy horses. Can. Vet. J., 55: 334-340.

26. Kim, T., M. Jang, H. Lee and I. Lee, 2012. Sedative and analgesic effects of intravenous detomidine and tramadol on horses. J. Vet. Clin., 29: 226-232.

27. Wagner, A.E., W.W. Muir and K.W. Hinchcliff, 1991. Cardiovascular effects of xylazine and detomidine in horses. Am. J. Vet. Res., 52: 651-657.

28. Yamashita, K., S. Tsubakishita, S. Futaok, I. Ueda and H. Hamaguchi et al., 2000. [Surgery: Effects of medetomidine, detomidine and xylazine on the cardiovascular system in horses (In Japanese)]. J. Vet. Med. Sci., 62: 1025-1032. 
29. Kinter, C.K., M.A. Gorko and E. Schaefer, 2019. The effects of xylazine administration on peripheral leukocyte values in thoroughbred horses. J. Equine Vet. Sci., Vol. 81,

30. Hamad, A.A., F.A. Torad, N.S. Thabet and S.M. Gadallah, 2016. Effect of tramadol versus fentanyl on some hematological and serum biochemical parameters in dogs. Alexandria J. Vet. Sci., 50: 122-129.

31. Rezende, M.L., K.N. Grimsrud, S.D. Stanley, E.P. Steffey and K.R. Mama, 2015. Pharmacokinetics and pharmacodynamics of intravenous dexmedetomidine in the horse. J. Vet. Pharmacol. Ther., 38: 15-23.

32 Solano, A.M., A. Valverde, A. Desrochers, S. Nykamp and L.P. Boure, 2009. Behavioural and cardiorespiratory effects of a constant rate infusion of medetomidine and morphine for sedation during standing laparoscopy in horses. Equine Vet. J., 41: 153-159.

33. England, G.C. and K.W. Clarke, 1996. Alpha 2 adrenoceptor agonists in the horse--a review. Br. Vet. J., 152: 641-657.

34. Ruohonen, S.T., S. Ruohonen, R. Gilsbach, E. Savontaus, M. Scheinin and L. Hein, 2012. Involvement of a2-adrenoceptor subtypes $\mathrm{A}$ and $\mathrm{C}$ in glucose homeostasis and adrenaline-induced hyperglycaemia. Neuroendocrinol., 96: 51-59.

35. Ambrisko, T.D. and Y. Hikasa, 2002. Neurohormonal and metabolic effects of medetomidine compared with xylazine in beagle dogs. Can. J. Vet. Res., 66: 42-49.
36. Kanda, T. and Y. Hikasa, 2008. Neurohormonal and metabolic effects of medetomidine compared with xylazine in healthy cats. Can. J. Vet. Res., 72: 278-286.

37. Dijk, P.V., D.P.K. Lankveld, A.B.M. Rijkenhuizen and F.H. Jonker, 2003. Hormonal, metabolic and physiological effects of laparoscopic surgery using a detomidine-buprenorphine combination in standing horses. Vet. Anaesth. Analg., 30: 71-79.

38. Maxwell, L.K., S.M. Thomasy, N. Slovis and C. Kollias-Baker, 2003. Pharmacokinetics of fentanyl following intravenous and transdermal administration in horses. Equine Vet. J., 35: 484-490.

39. Trim, C.M. and R.R. Hanson, 1986. Effects of xylazine on renal function and plasma glucose in ponies. Vet. Rec., 118: 65-67.

40. Kaneko, J.J., J.W. Harvey and M.L. Bruss, 1997. Clinical Biochemistry of Domestic Animals. 5th Edn., Academic Press, San Diego, California, ISBN-13: 9780123963055, Pages: 932.

41. Funcia, J.P., R. Lamuraglia, A. Guglielminetti, M. Soriano and L.M. Melo, 2016. Preliminary results of behavioral and cardiopulmonary effects of a constant rate infusion of remifentanil-xylazine for sedation in horses. J. Equine Vet. Sci., 37: 49-53.

42. Krapf, R., P. Caduff, P. Wagdi, M. Staubli and H.N. Hulter, 1995. Plasma potassium response to acute respiratory alkalosis. Kidney Int., 47: 217-224. 